\title{
El refuerzo de los alimentos con ácido fólico sería suficiente para prevenir los defectos del tubo neural
}

Minimum effective dose of folic acid for food fortificaction to prevent neural-tube defects.

Sean D, Mills JL, Conley M et al. Lancet.1997;350:1666-69.

\section{Objetivo}

Determinar la mínima dosis que debería adicionarse a los alimentos para lograr una concentración de ácido fólico (AF) en los eritrocitos que prevenga los defectos del tubo neural (DTN) $(400 \mu \mathrm{g} / \mathrm{L})$.

\section{Diseño}

Estudio randomizado controlado doble ciego. Seis meses de seguimiento.

\section{Lugar}

Dublin, Irlanda.

\section{Pacientes}

Se randomizaron 121 empleadas del Coombe Women's Hospital de Dublin con dosaje de ácido fólico eritrocitario (A.FE) de
$150-400 \mu \mathrm{g} / \mathrm{L}$. Se excluyeron las mujeres con concentraciones $<150$ $\mu \mathrm{g} / \mathrm{L}$ (por alto riesgo de DTN en sus hijos). También se excluyeron mujeres con concentraciones $>400 \mu \mathrm{g} / \mathrm{L}$ ya que estos valores se consideran protectores para DTN. Otros criterios de exclusión fueron : embarazadas o con posibilidad de estarlo, tomadoras de AF o B12, planificación de embarazo, antecedentes de dos o más abortos consecutivos, antecedentes de enfermedad o cirugía gastrointestinal o enfermedad hepática en el momento del estudio. El seguimiento fue del $78 \%$.

\section{Intervención}

Las pacientes fueron randomizadas para recibir placebo $(n=29)$ o AF: $100 \mathrm{mg}(\mathrm{n}=30), 200 \mathrm{mg}(\mathrm{n}=31)$ o $400 \mathrm{mg}(\mathrm{n}=31)$.

\section{Medición de resultados principales}

El resultado principal fue la concentración de AFE.

\section{Resultados principales}

$\mathrm{El}$ análisis fue por intención de tratar*.

AFE e impacto estimado de la intervención

\begin{tabular}{|c|c|c|c|c|c|c|}
\hline \multirow[t]{2}{*}{ Grupo } & \multicolumn{2}{|c|}{ AFE mediana (IC 95\%) $\mu \mathrm{g} / \mathrm{L}$} & \multicolumn{2}{|c|}{$\begin{array}{l}\text { Riesgo estimado de } \\
\text { DTN/1000nacimientos }\end{array}$} & \multirow[t]{2}{*}{$\begin{array}{c}\text { RRR } \\
\%\end{array}$} & \multirow[t]{2}{*}{$\begin{array}{c}\text { NNT } \\
\text { estimado }\end{array}$} \\
\hline & Inicial & Final & Inicial & Final & & \\
\hline Placebo $(n=19)$ & $335(306-388)$ & $311(171-343)$ & 1.6 & 1.7 & 0 & - \\
\hline $\mathrm{AF} 100 \mu \mathrm{g}(\mathrm{n}=22)$ & $309(291-371)$ & $375(354-444) *$ & 1.8 & 1.4 & 22 & 250 \\
\hline AF $200 \mu \mathrm{g}(n=28)$ & $311(291-337)$ & $475(432-503) *$ & 1.7 & 1.1 & 41 & 170 \\
\hline AF $400 \mu g(n=26)$ & $350(319-399)$ & $571(481-654)^{*}$ & 1.5 & 0.8 & 47 & 140 \\
\hline
\end{tabular}

$* p<0.001$

\section{Conclusiones}

El incremento detectado de la concentración de AFE en el grupo que recibió un suplemento de $200 \mathrm{mg}$ puede prevenir los defectos del tubo neural. Si nos basamos en el incremento del gru-

po que recibió $100 \mathrm{mg}$, es probable que esta dosis tomada en forma continua también reduzca la incidencia de defectos del tubo neural.

\section{Comentario}

La eficacia del suplemento con AF en el período periconcepcional para prevenir defectos del tubo neural está claramente demostrada. Actualmente existe una recomendación tipo A* para suministrar $400 \mu \mathrm{g} /$ día $(0.4 \mathrm{mg})$ de $\mathrm{AF}$ a toda mujer en edad fértil que busca un embarazo y hasta el primer trimestre de gestación inclusive (1). Sin embargo la adherencia a esta medida es muy baja por tres causas principales: la mayoría de los embarazos no son planificados, muchas mujeres no consultan antes de embarazarse y muchos médicos desconocen esta indicación. Por lo tanto la fortificación de los alimentos sería una medida efectiva para prevenir los defectos del tubo neural ya que el suplemento de AF estaría universalmente distribuido. Este estudio demuestra que una mínima dosis de 100 a $200 \mu$ g elevaría el AFE a niveles que reducirían la incidencia de DTN. Se excluyeron las mujeres con concentraciones menores a $150 \mu \mathrm{g} / \mathrm{L}$ (por alto riesgo de DTN en sus hijos) ya que la inclusión de este subgrupo no sería ética. En este estudio un $4.3 \%$ de las mujeres convocadas fueron excluidas por esta razón. Por lo tanto la dosis de suplementación recomendada en el presente estudio podría ser insuficiente para este subgrupo de pacientes de alto riesgo. De todos modos este estudio es un interesante puntapié inicial para determinar la mínima dosis efectiva para prevenir defectos del tubo neural sin enmascarar anemia perniciosa (recordemos que si se fortifican los alimentos, el AF será recibido por toda la población, no sólo mujeres en edad fértil). Por el momento todos los médicos de atención primaria debemos recomendarle a nuestras pacientes que buscan embarazo la prescripción de $0.4 \mathrm{mg}$ por día de AF hasta el primer trimestre del embarazo inclusive. Esta dosis debe elevarse a $4 \mathrm{mg}$ por día en mujeres con antecedentes de hijos con defectos del tubo neural.

*Ver Glosario

Karin Kopitowshi Unidad de Medicina Familiar y Preventiva Hospital Italiano de Buenos Aires

\section{Referencias}

1. US Preventive Services Task Force. Guide to clinical preventive services, 2ed. Baltimore: Wiliams \& Wilkins, 1996.pp467-483 